\title{
Understanding Eurovision tele-voting through modelling
}

\author{
A.H. Dekker \\ Dekker Consulting, P.O. Box 3925, Manuka, ACT, 2603, Australia \\ Email: dekker@acm.org
}

\begin{abstract}
The Eurovision Song Contest has been held since 1956, providing European countries an opportunity to vote on other countries' songs. Voting has long been controversial, however, with accusations of unfairness and collusion. In this paper we model the tele-voting by members of the public in the most recent (2021) competition. Our goal is to determine to what extent a simple model with known factors can explain the results. Our model is based on five factors, three of which apply to some countries only:
\end{abstract}

- Quality-based (Q) voting

- Expatriate $(\alpha)$ voting (people in country A with ancestry from country B voting for country B)

- Nordic $(\beta)$ voting (some countries only)

- Singer-based $(\gamma)$ voting (some countries only)

- Covid-based $(\delta)$ voting (some countries only)

We simulated the voting for a sample of 15 countries. Table 1 summarises our results. Our main measure of performance was the mean absolute error in simulating actual tele-voting scores from the event. The mean absolute error was 20.7, with the best match to real data being Norway, and the worst being France.

The performance of the model suggests that no large additional factors contribute to the voting outcomes, although a better fit to the real data would be obtained by explicitly modelling differences in taste between countries and by having a better model of how likely expatriate voters are to vote for their "home country."

Table 1. Experimental results

\begin{tabular}{|c|c|c|c|c|c|c|}
\hline $\begin{array}{l}\text { Voting } \\
\text { Country }\end{array}$ & $\begin{array}{l}\text { Country } \\
\text { Cluster }\end{array}$ & Model & $\alpha$ votes & $\beta / \gamma / \delta$ votes & $\begin{array}{c}\text { Absolute } \\
\text { Error }\end{array}$ & $\mathbf{R}^{2}$ \\
\hline Norway & Nordic & $\mathbf{Q}+\alpha \mathbf{E} / \mathbf{G}+\beta \mathbf{X}_{\text {Nordic }}$ & $16.5 \%$ & $13.9 \%$ & 8 & $96.2 \%$ \\
\hline Spain & - & $\mathbf{Q}+\alpha \mathbf{E} / \mathbf{G}$ & $8.3 \%$ & & 12 & $93.7 \%$ \\
\hline Israel & - & $\mathbf{Q}+\alpha \mathbf{E} / \mathbf{G}$ & $15.6 \%$ & & 12 & $91.3 \%$ \\
\hline Latvia & Western & $\mathbf{Q}+\alpha \mathbf{E} / \mathbf{G}+\beta \mathbf{X}_{\text {Nordic }}$ & $41.6 \%$ & $9.9 \%$ & 16 & $89.6 \%$ \\
\hline Greece & Greek & $\mathbf{Q}+\alpha \mathbf{E} / \mathbf{G}+\gamma \mathbf{X}_{\text {Singer }}$ & $8.4 \%$ & $8.1 \%$ & 16 & $85.9 \%$ \\
\hline Denmark & Nordic & $\mathbf{Q}+\alpha \mathbf{E} / \mathbf{G}+\beta \mathbf{X}_{\text {Nordic }}$ & $10.0 \%$ & $24.9 \%$ & 16 & $83.2 \%$ \\
\hline Australia & Western & $\mathbf{Q}+\alpha \mathbf{E} / \mathbf{G}+\delta \mathbf{X}_{\text {Covid }}$ & $11.1 \%$ & $15.4 \%$ & 18 & $80.4 \%$ \\
\hline Slovenia & Balkan & $\mathbf{Q}+\alpha \mathbf{E} / \mathbf{G}$ & $18.5 \%$ & & 22 & $72.7 \%$ \\
\hline Cyprus & Greek & $\mathbf{Q}+\alpha \mathbf{E} / \mathbf{G}+\gamma \mathbf{X}_{\text {Singer }}$ & $11.4 \%$ & $5.7 \%$ & 22 & $73.9 \%$ \\
\hline Switzerland & Balkan & $\mathbf{Q}+\alpha \mathbf{E} / \mathbf{G}$ & $50.0 \%$ & & 24 & $76.7 \%$ \\
\hline Netherlands & - & $\mathbf{Q}+\alpha \mathbf{E} / \mathbf{G}+\gamma \mathbf{X}_{\text {Singer }}$ & $0 \%$ & $6.8 \%$ & 26 & $55.0 \%$ \\
\hline Czech Republic & French & $\mathbf{Q}+\alpha \mathbf{E} / \mathbf{G}$ & $47.8 \%$ & & 28 & $67.4 \%$ \\
\hline United Kingdom & - & $\mathbf{Q}+\alpha \mathbf{E} / \mathbf{G}+\delta \mathbf{X}_{\text {Covid }}$ & $10.5 \%$ & $16.4 \%$ & 28 & $66.9 \%$ \\
\hline Germany & Western & $\mathbf{Q}+\alpha \mathbf{E} / \mathbf{G}+\delta \mathbf{X}_{\text {Covid }}$ & $5.0 \%$ & $17.3 \%$ & 30 & $70.1 \%$ \\
\hline France & French & $\mathbf{Q}+\alpha \mathbf{E} / \mathbf{G}$ & $17.3 \%$ & & 32 & $62.8 \%$ \\
\hline Mean & & & & & 20.7 & $77.7 \%$ \\
\hline
\end{tabular}

Keywords: Voting, Eurovision, Stochastic modelling 


\section{INTRODUCTION}

The Eurovision Song Contest has been held in a gradually expanding Europe since 1956, and has been broadcast in Australia since 1983. Famous winners include ABBA (representing Sweden in 1974) and Céline Dion (representing Switzerland in 1988). Participating countries, including those eliminated before the final, vote on the finalists. Since 1998, this voting has been totally or partially based on tele-voting from individual members of the public. That is, people within the voting country can register a preference for a song (other than the country's own song) by dialling a telephone number or sending a SMS message. Generally this voting can be done multiple times, but with varying limits on the number of times. In Australia, the cost per vote is 55c. In Europe, the cost per vote ranges from the equivalent of $20 \mathrm{c}$ to $\mathrm{A} \$ 2.30$.

Tele-votes are translated into scores by assigning 12 points to the song with the most votes, 10 to the song with the second most votes, 8 to the song with the third most votes, 7, 6, 5, 4, 3, 2, and 1 to the next seven songs, and 0 points to all other songs.

Voting in the Eurovision Song Contest has been controversial for many years (Yair, 1995; Fenn et al, 2006; Gatherer, 2006; Dekker, 2008; Spierdijk and Vellekoop, 2009). There have been accusations of unfairness and collusion. In this paper we use a simple simulation model to explore the tele-voting process. In particular, we are interested in the extent to which known factors can explain the patterns of tele-voting.

\section{OUR MODEL AND EXPERIMENT}

Our simple model incorporates voting for a song based on its perceived "quality," the well-known phenomenon of expatriate voting, and three other features which applied only to certain countries.

Data was taken from the fan website at eurovisionworld.com, and related to the final of the most recent (2021) competition.

\subsection{Quality-based voting: $Q$}

We assume that a substantial fraction of tele-voters vote for what they believe to be the song of highest quality. In particular, we assume that the probability of a given individual voting for the various songs is proportional to the quality $\mathbf{Q}$ of those songs, and that the quality can be estimated by the final competition scores (which combine tele-votes with the votes of nation juries).

That is, we assume that $\mathbf{Q}=$ Italy (524), France (499), Switzerland (432), Iceland (378), Ukraine (364), ... sixteen other countries ..., San Marino (50), Netherlands (11), Spain (6), Germany (3), United Kingdom (0).

There are three problems with this assumption. First, these scores combine a great many social and taste factors, and do not really measure "quality" in any objective sense. Second, these scores provide an after-thefact assessment of "quality" which has explanatory, but not predictive, value. To actually predict winners of the contest, one might wish to apply deep learning to the music tracks themselves, in order to identify characteristics that make a song likely to win. However, such analysis is outside the scope of the present work.

The third problem is that there is no single European taste when it comes to Eurovision songs. Indeed, in 2021, six countries (Iceland, Lithuania, Greece, Moldova, Serbia, and Cyprus) received the maximum score of 12 from at least two countries, while also receiving the minimum score of 0 from at least two countries.

Figure 1 shows the result of a hierarchical clustering analysis (UPGMA: unweighted pair group method with arithmetic mean) on the tele-vote scores of the 39 voting countries in 2021 . Since there were 26 contestants in the final, each voting country's tele-vote scores formed a 26-element vector. Each voting country's own song was assigned 12 points, and the hierarchical clustering analysis was performed on the matrix of Euclidean distances between the modified vectors.

There are five main clusters in Figure 1 (with 8 countries not assigned to a major cluster):

- a Greek-dominated cluster containing Greece, Cyprus, San Marino, and Georgia

- a Nordic cluster containing four of the five Nordic countries plus Malta

- a Western cluster of 11 countries (including Australia, Poland, Ukraine, and the Baltics)

- a Balkan cluster of 6 countries (also containing Austria and Switzerland)

- a cluster containing France and four other countries 


\section{Eurovision Song Contest 2021: Tele-Voting Similarities}

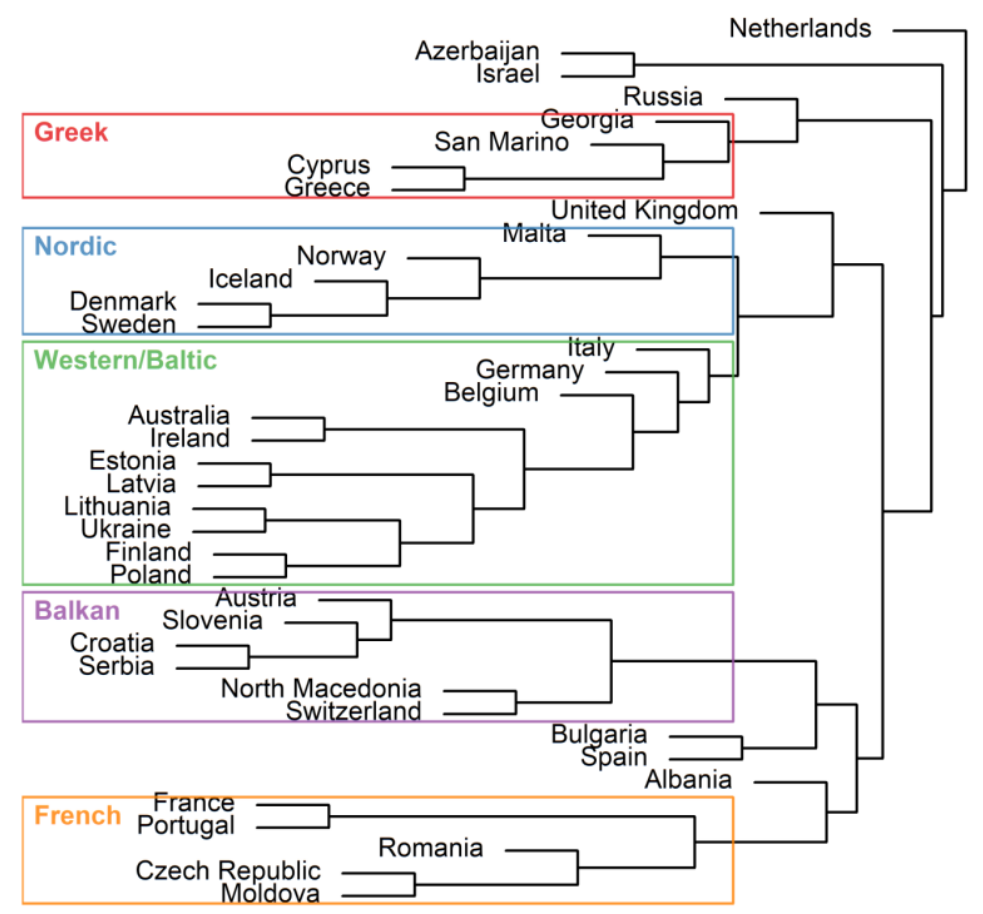

Figure 1. Hierarchical clustering (UPGMA) analysis on Eurovision tele-vote scores.

The Nordic and Western clusters are very close in voting patterns, differing mostly in the Nordic preference for other Nordic countries. Because of fragmentation in the Eastern European vote, the Nordic and Western clusters largely determined the tele-voting outcome. This means that our experimental results are better for countries in the Nordic and Western clusters, like Norway and Australia, than for countries outside them, like France or Greece (although this difference is not statistically significant).

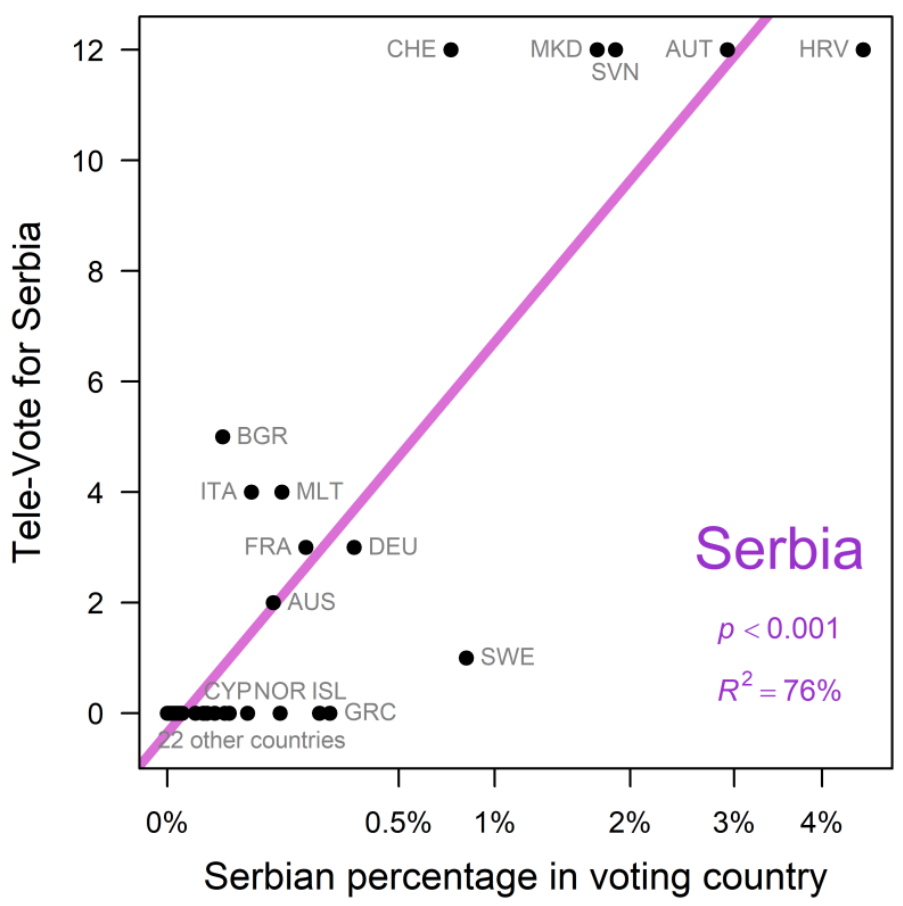

Figure 2. Expatriate voting explains $76 \%$ of the variance of the votes for Serbia (data on Serbian percentage of population is from a number of sources from the period 2010 to 2021 , and is not of uniform quality). 


\subsection{Expatriate voting: $\alpha \mathrm{E} / \mathrm{G}$}

It has long been known (see e.g. Dekker, 2008) that expatriate voting plays a large part in Eurovision televoting. That is to say, individuals in country A whose citizenship or ancestry lies in country B have a tendency to vote for country B's entry regardless of song "quality." As an example, Figure 2 shows that such expatriate voting explains $76 \%$ of the variance of the votes for Serbia. Since there is a financial cost associated with tele-voting, this kind of "ethnic pride" provides a motivation to vote which a mere aesthetic preference might not provide.

One difficulty in analysing this effect is that it is not entirely clear who should count as an "expatriate." Another is that available data on expatriate numbers is neither complete nor entirely accurate. A third difficulty is that the probability that individuals in country A linked to country B will vote for country B's song depends on the characteristics of both countries.

In our model, we assume that a certain number of people in country A will blindly vote for their ancestral country B, based on a vector $\mathbf{E}$ of expatriate numbers within country A. This is in addition to the votes for that country based on "quality."

Since this expatriate effect seems to be stronger for smaller and/or poorer countries B, we scale this by a vector $\mathbf{G}$ of the square roots of GDP for the various countries. We multiply by a tuneable parameter $\alpha$, to give $\alpha \mathbf{E} / \mathbf{G}$.

\subsection{Nordic voting: $\boldsymbol{\beta} \mathbf{X}_{\text {Nordic }}$}

As already noted, there is a tendency for the Nordic countries Norway, Sweden, Finland, Denmark, and Iceland to vote for each other (although Finland was not part of the Nordic cluster in Figure 1). In our model, we assume that a certain number of people in the Nordic countries (and also in the Baltic countries Latvia, Lithuania, and Estonia) will randomly vote for a Nordic song, regardless of song "quality." This Nordic vote may represent a distinct regional "taste" in music, or it may reflect Nordic expatriates not included in the available data.

We quantify this effect, where it applies, with a tuneable parameter $\beta$ multiplied by a characteristic vector $\mathbf{X}_{\text {Nordic }}$ which is 1 for the five Nordic countries and 0 for other countries, to give $\beta \mathbf{X}_{\text {Nordic. }}$

\subsection{Singer-based voting: $\gamma \mathbf{X}_{\text {Singer }}$}

Some voting countries in the 2021 Eurovision contest had a strong connection with a specific singer. For example, Greece had a strong vote for Elena Tsagrinou, the Greek singer representing Cyprus. The Netherlands had a strong vote for the singer Stefania who represented Greece, given that she was not only born in, but remains resident in, the Netherlands.

We quantify this effect, where it applies, with a tuneable parameter $\gamma$ multiplied by a characteristic vector $\mathbf{X}_{\text {Singer }}$ which is 1 for the specific singer's country and 0 for other countries, to give $\gamma \mathbf{X}_{\text {Singer }}$.

\subsection{Covid-based voting: $\delta \mathbf{X}_{\text {Covid }}$}

The 2021 Eurovision contest was held in the shadow of Covid-19 and associated lockdowns. The Lithuanian entry, sung by the group Discoteque, contained the line "There's no one here and I don't care, I feel it's safe to dance alone," which was widely regarded as a comment on Covid-19.

In addition, due to a positive Covid-19 test result, the group Daði \& Gagnamagnið from Iceland was not permitted to perform in the final, and competed based on footage from a rehearsal recorded 9 days earlier.

There were some indications that the shared experience of Covid-19 led some people in Australia, Germany, and the United Kingdom to give a "sympathy vote" to Lithuania and Iceland.

We quantify this effect with a tuneable parameter $\delta$ multiplied by a characteristic vector $\mathbf{X}_{\text {Covid }}$ which is 1 for Lithuania and Iceland and 0 for other countries, to give $\delta \mathbf{X}_{\text {Covid. }}$

\subsection{The Experiment}

For given values of $\alpha$ (and where relevant, $\beta, \gamma$, or $\delta$ ), the (relative) expected numbers of tele-votes from each country could be calculated analytically, so that Monte Carlo simulation was not needed. We used simulated annealing to find optimal values of $\alpha, \beta, \gamma$, and $\delta$. Numbers of tele-votes were then converted to scores based on the contest rules. 
Given the limited data on expatriate populations, we focussed on a representative sample of 15 of the 39 voting countries, listed in Table 1. As measures of performance, we used the sum of the absolute errors in the simulated scores as well as the $\mathrm{R}^{2}$ value. Optimisation was based on minimising the absolute errors.

\section{RESULTS}

Table 1 summarises the experimental results, and Figure 3 shows detailed results for Norway, Greece, Australia, and France. Absolute errors ranged from 8 (for Norway) to 32 (for France), with a mean of 20.7. For comparison, purely random guesses give a mean absolute error of 84.8 . The $\mathrm{R}^{2}$ values ranged from $55.0 \%$ (for the Netherlands) to $96.2 \%$ (for Norway), with a mean of $77.7 \%$.

The fraction of quality-based votes ranged from $48.5 \%$ (for Latvia) to $93.2 \%$ (for the Netherlands). Expatriate $(\alpha)$ votes ranged from $0 \%$ (for the Netherlands: clearly an underestimate) to $50 \%$ (for Switzerland). Other large effects included $13.9 \%$ of Nordic $(\beta)$ votes in Norway, $24.9 \%$ of Nordic $(\beta)$ votes in Denmark, $8.1 \%$ of singer-based $(\gamma)$ votes in Greece, and $15.4 \%$ of Covid-based $(\delta)$ votes in Australia.

As noted above, results were worse for countries outside the Western and Nordic clusters. For example, the model predicted that the Netherlands would give 12 points to Italy (the winner), but in fact only two points were awarded. The model also failed to predict the 6 points awarded by the Netherlands to Portugal, which seems to be at least partly due to Portuguese expatriates. Expatriate votes were also grossly underestimated in Germany, especially those for Serbia. At Eurovision, Switzerland gave 12 points to Serbia and 7 points to Albania; our model reversed these scores.

The model's worst result was for France, with an absolute error of 32. This error was due to multiple small overestimates, combined with a gross underestimate of Ukrainian and Moldovan expatriate votes. The failure of the model here appears to be connected to the difference between French musical tastes and those of other Western countries.

On the whole, however, the mean absolute error of 20.7 and mean $\mathrm{R}^{2}$ of $77.7 \%$ represent a reasonable performance for a very simple model. This suggests that no large additional factors contribute to the voting outcomes.

\section{DISCUSSION}

Our results demonstrate that our simple model can indeed explain a large part of the results, though with significant errors for some countries, such as France. In particular, the results suggest that, while $48.5 \%$ or more of Eurovision tele-votes are based on personal assessments of song "quality," up to $50 \%$ of tele-votes are expatriate votes motivated purely by ethnicity. This is in line with past studies (e.g. Dekker, 2008).

Our model could be improved in three main ways. First, we could incorporate differences in national taste, by using data from past competitions. Second, we could also incorporate Europe-wide scaling factors representing the tendencies of different ethnicities to engage in expatriate voting. Such an improved model is likely to give a better fit to the data and to give even higher estimates of the amount of expatriate voting. Stockemer et al. (2018) suggest that $36 \%$ of tele-voters may be engaging in expatriate voting, or regional voting, or preferences for specific countries. This is in line with our experimental results, and can generate large scores for otherwise unpopular songs. Whether that is undesirable or not is a matter of opinion.

Finally, we could also improve our model by generalising Nordic voting and singer-based voting to have a single parameter and a network of a priori network relationships between countries, and by generalising Covid-based voting to have a single parameter and a vector of media portrayal scores for various countries (that is, high scores for countries covered in a sympathetic way, and low scores for countries portrayed negatively).

There is a weak $\left(\mathrm{R}^{2}=22 \%\right)$, though non-significant, positive correlation between our model's prediction of quality-based voting and the cost of tele-voting. This suggests one possible avenue for reducing expatriate voting, if that should indeed be a desirable outcome.

It seems clear, though, that the Eurovision Song Contest continues to be an interesting window into European attitudes. Continued research into the competition is likely to generate further insights. 
Dekker, Understanding Eurovision tele-voting through modelling

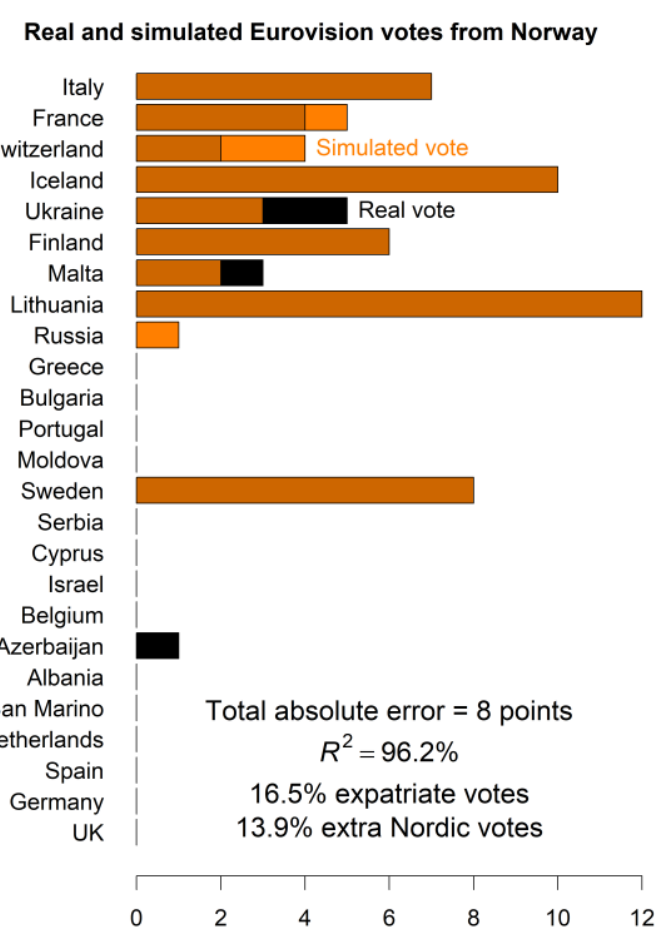

Real and simulated Eurovision votes from Australia

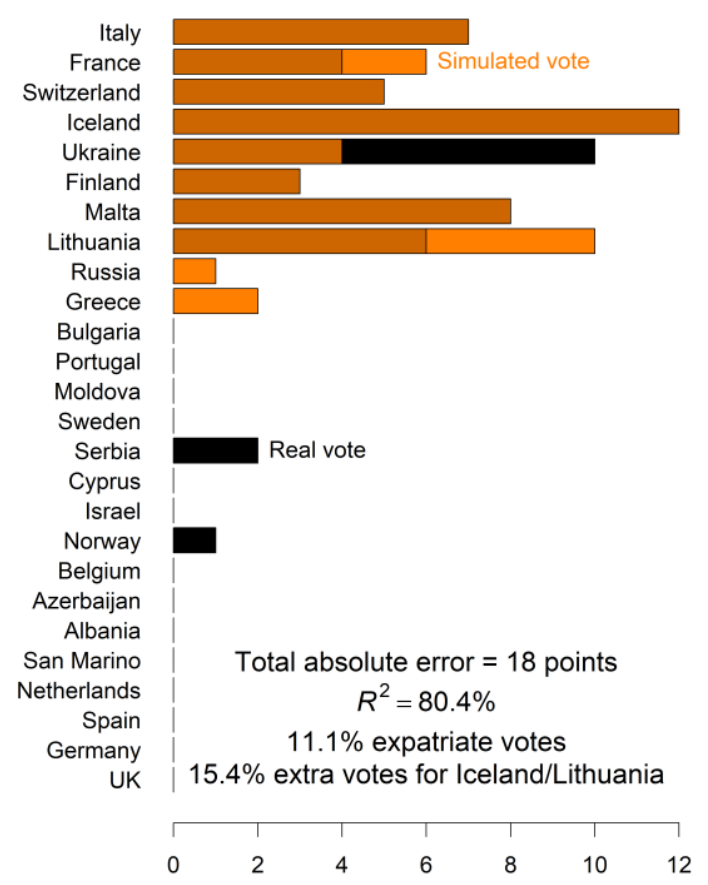

Real and simulated Eurovision votes from Greece

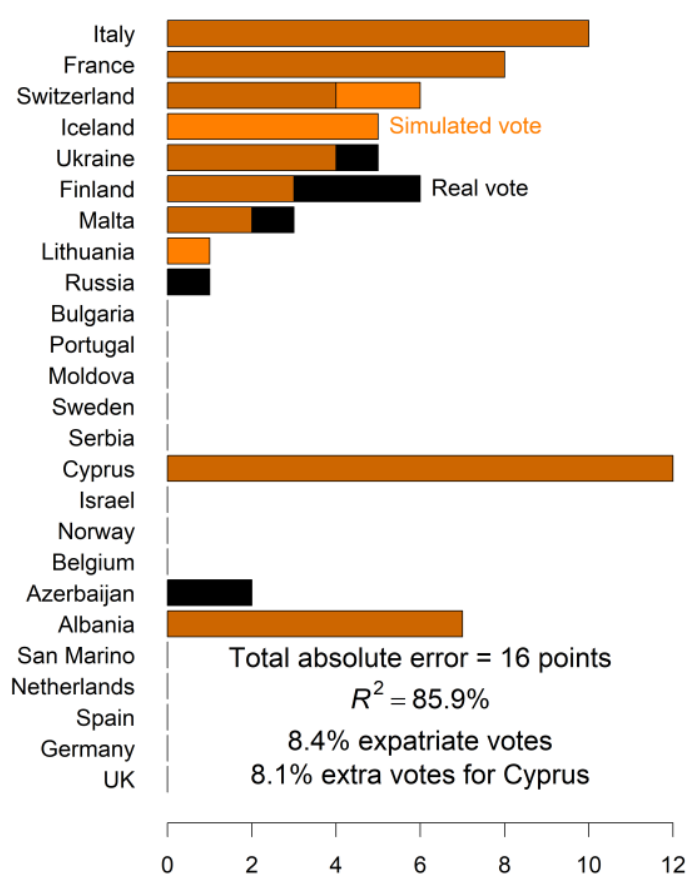

Real and simulated Eurovision votes from France

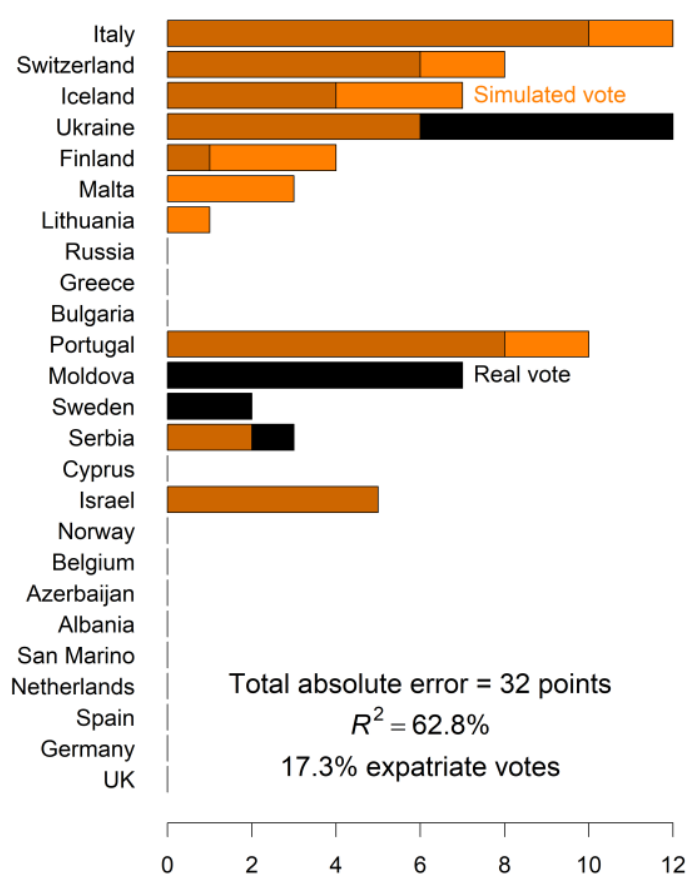

Figure 3. Results for 4 of the 12 countries modeled. Black bars show the actual scores awarded at Eurovision, and orange bars show simulated scores. Where these bars agree, they are brown.

\section{REFERENCES}

Dekker, A.H., 2008. The Eurovision Song Contest as a 'Friendship' Network. Connections 28(1), 59-72. assets.noviams.com/novi-file-uploads/insna/Connections_Archive/2008 Volume 28 Issue 1.pdf

Fenn, D., Suleman, O., Efstathiou, J., Johnson, N.F., 2006. How does Europe Make Its Mind Up? Connections, cliques, and compatibility between countries in the Eurovision Song Contest. Physica A 360(2), 576-598 
Dekker, Understanding Eurovision tele-voting through modelling

Gatherer, D., 2006. Comparison of Eurovision Song Contest Simulation with Actual Results Reveals Shifting Patterns of Collusive Voting Alliances. Journal of Artificial Societies and Social Simulation 9(2): jasss.soc.surrey.ac.uk/9/2/1.html

Spierdijk, L., Vellekoop, M., 2009. The structure of bias in peer voting systems: lessons from the Eurovision Song Contest. Empirical Economics 36, 403-425. doi:10.1007/s00181-008-0202-5

Stockemer D, Blais A, Kostelka F, Chhim C., 2018. Voting in the Eurovision Song Contest. Politics 38(4), 428-442. doi:10.1177/0263395717737887

Yair, G., 1995. 'Unite Unite Europe' The political and cultural structures of Europe as reflected in the Eurovision Song Contest. Social Networks 17(2), 147-161. 